ИЗВЕСТИЯ АКАДЕМИИ НАУК ЭСТОНСКОИ ССР ТОМ VI

СЕРИЯ БИОЛОГИЧЕСКАЯ. 1957, № 2

\title{
BIOLOOGILISELT AKTIIVSETEST AINETEST HAAPSALU RAVIMUDAS (HUMIINHAPPED)
}

\author{
E. KEEL
}

Mudade ravitoimet seostatakse tavaliselt nende füüsikalis-keemiliste omadustega, soojustoimega ja soolade sisaldusega $\left.{ }^{22}\right]$. Mudade orgaaniliste koostisainete spetsiffilist toimet pole seni veel tõsisemalt arvestatud, kuigi kirjanduses esineb vastavaid viiteid.

Viimase kümne aasta jooksul eraldati mudadest mitmeid ravimpreparaate (peloidodestillaat, peloidiin jt.), mida kasutati kui biogeenseid stimulaatoreid sisaldavaid ravimeid väga mitmesuguste haiguste raviks. Mudadest orgaaniliste lahustitega eraldatud fraktsioonidel täheldati antibakteriaalseid omadusi $\left[{ }^{6}, 7\right]$.

Uuemates uurimustes ravimudade orgaaniliste koostisainete alal on eriti esile tõstetud humiinhappeid kui bioloogiliselt aktiivseid aineid $\left.{ }^{18}\right]$. E. Hiller näitas, et salitsüliseeritud humiinhapete kümblustega ${ }^{16}{ }^{16}$ võib saada hüpofüüsi - neerupealisekoore hormoonsüsteemi aktiviseerimist ning humiinhapete kümblustega [ $\left.{ }^{17}\right]$ olulist môju ferment hüaluronidaasile. V. A. Biber ja N. S. Bogoljubova näitasid limaanimudast, mustmullast ja turbast eraldatud humiinhapete bioloogilise aktiivsuse ühtsust akadeemik V. P. Filatovi biogeensete stimulaatoritega $\left[{ }^{4,5}\right.$, . Lahused, mis sisaldavad $0,001-0,0001 \%$ humiinhappeid, stimuleerivad taimede elutegevust, suuremates kontsentratsioonides aga pidurdavad $\left[{ }^{12}\right]$. Humiinhapped väldivad taimede raudkloroosi $\left[{ }^{19}\right]$.

Môned ravimudade orgaanilist koostist uurinud autorid täheldasid, et need sisaldavad mikroelemente kindlas kvantitatiivses vahekorras mudade orgaanilise ainega [ $\left.{ }^{11}\right]$. N. M. Tšistjakov $\left[{ }^{15}\right]$ täheldas Varzi-Jattši ravimudades vase, nikli ja mangaani hulga olenevust humiinhappeist. Ơleliidulisel hüdrokeemia nōupidamisel juhiti tähelepanu ravimudade orgaaniliste ainete ja mikroelementide vastastikuse mōju ja sèose selgitamise vajadusele [1].

Lähtudes vajadusest anda mudade ravitoime küsimusele senisest täielikumat seletust, eraldati käesolevas töös Haapsalu ravimudast humiinhapete fraktsioon, mille mōningaid üldisi bioloogilisi omadusi uuriti.

\section{Humiinhapete eraldamine}

Haapsalu ravimuda kuivjääk sisaldab N. A. Derbentseva [ $\left.{ }^{7}\right]$ andmeil $7,35 \%$ orgaanilisi aineid, millest $59,01 \%$ moodustab ligniin-huumuselise kompleksi. Oma uurimisteks kasutasime 1954. a. sügisel võetud muda, mida säilitati hermeetiliselt suletud nöus. Humiinhapete eraldamiseks kasutati alljärgnevat, lihtsustatud tehnoloogilise protsessiga meetodit. Selles ei rakendatud, erinevalt kirjanduses esitatud eeskirjadest, dekaltsineerimise, biitumifraktsiooni eraldamise ja dialüüsi protsesse. Leelishüdroksüüd asendati leeliskarbonaadiga, humiinhappeid hapendumise eest kaitsva $\mathrm{CO}_{2}$ atmosfääri tekitamiseks. Humiinhapete naatriumisoolad eraldati sadestamisega, lisades alkoholi.

Eraldamise käik. Muda (kasutatul oli kuivjääki 22,6\%) ekstraheeritakse algul külmalt (seismisel üle öö) võrdse kaaluhulga $3 \%$-lise $\mathrm{Na}_{2} \mathrm{CO}_{3}$ lahusega. Segu soojendatakse siis 1 tund vesivannil $70^{\circ}$ juures. Peale jahtumist lahustamatud osad eraldatakse ekstraktist tsentrifugeerimisel. Algekstrakti hapustatakse $2 \mathrm{~N}$ soolhappega (kuni pH 4) ja soojendatakse siis 1 tund keeval vesivannil. Pärast jahtumist neutraliseeritakse $0,5 \mathrm{~N}$ naatriumkarbonaadilahuse lisamisega kuni $\mathrm{pH} 7,1$. Humiinhapete eraldamiseks lisa- 
takse ekstraktile võrdne mahuosa etüülalkoholi, mis tekitab mahuka kolloidaalse sademe, mis eraldatakse tsentrifugeerimisega. Viimast tihendatakse ja puhastatakse alkoholi teistkordse lisamisega ja tsentrifugeerimisega. Sade lahustatakse destilleeritud vees, alkohol eemaldatakse soojendamisega vesivannil ja lahust täiendatakse destilleeritud veega algekstrakti kaaluni. Preparaat täidetakse ampullidesse, steriliseeritakse 1 tund $120^{\circ}$ juures. Saadud humiinhapete lahus (HL) on pruuni värvusega neutraalse reaktsiooniga selge vedelik, mis sisaldab $0,24 \%$ kuivainet. Mineraalhapete, kaltsium- või raudkloriidi lisamisel annab mahuka pruuni sademe.

Humiinhapete lahuse lähemaks keemiliseks iseloomustamiseks hapustati lahust $2 \mathrm{~N}$ soolhappega, lisati võrdne maht alkoholi ja tsentrifugeeriti. Sadet pesti korduvalt alkoholiga ning lõpuks mitu korda bensooliga, pärast bensooli aurustumist kuivatati $80-90^{\circ}$ juures. Saadud jäägis määrati orgaanilisel elementaaranalüüsil $\mathrm{C}$ ja $\mathrm{H}$ sisaldus. Leitud $\mathrm{C}$ hulk võeti humiinhapete kvantitatiivse sisalduse määramise aluseks, arvestades keskmise C-sisaldusena humiinhappeis $59 \%\left[{ }^{21}\right]$. Humiinhapete lahuse kuivjäägist tuha ja humiinhapete hulga mahaarvamisel saadi teiste orgaaniliste ainete (tõenäoliselt hümatomelaanhapped, biitumid) sisaldus. Selle järgi sisaldab HL tuhka $0,072 \%$, humiinhappeid $0,095 \%$, teisi orgaanilisi aineid $0,068 \%$ ning lahuse kuivjääk vastavalt $30,7 \%$ tuhka, $40,4 \%$ humiinhappeid, $28,9 \%$ teisi orgaanilisi aineid.

\section{Ravimudast eraldatud humiinhapete fraktsiooni bioloogiline iseloomustus}

Arvestades kirjanduse andmeid [4,5], mille järgi mustmulla, turba ja limaanimuda humiinhapped osutuvad bioloogiliselt aktiivseteks aineteks, osutus vajalikuks anda ka käesolevas artiklis ravimudast eraldatud humiinhapete fraktsioonile bioloogiline iseloomustus. Testidena kasutati akadeemik V. P. Filatovi soovitatud pärmi käärimise $\left[{ }^{[4]}\right.$, maisiseemnete idanemise ja nahadefekti paranemise $\left[{ }^{13}\right]$ määnamisi.

Joonistel 1 ja 2 esitatud kõverad näitavad, et humiinhapete mõõdukas
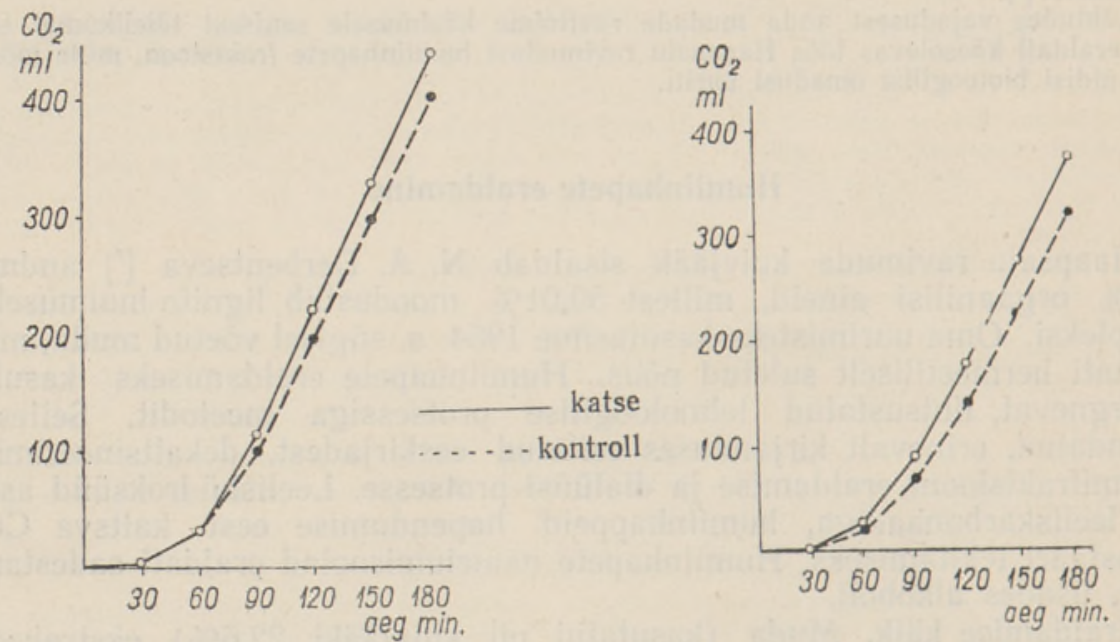

Joon. 1. HL mõju pärmi käärimisele. Pärmisuspensioon $0,85 \%$ lises $\mathrm{NaCl}$-lahuses -200 $\mathrm{ml}+20 \mathrm{~g}$ glükoosi $+5 \mathrm{ml} \mathrm{HL}$ (kontrollis $5 \mathrm{ml} 0,85 \%$-line $\mathrm{NaCl}$-lahus) temp. $35^{\circ}$.

Joon. 2. $\mathrm{HL}$ ja $\mathrm{MnSO}_{4}$ mõju pärmi käärimisele. Pärmisuspensioon $0,85 \%$-lises $\mathrm{NaCl}$-lahuses $-200 \mathrm{ml}+20 \mathrm{~g}$ glükoo$\mathrm{si}+5 \mathrm{ml} \mathrm{HL}, 1 \mathrm{mg} \mathrm{MnSO}_{4}$. . $5 \mathrm{H}_{2} \mathrm{O}$ (kontrollis $5 \mathrm{ml} 0,85 \%$ line $\mathrm{NaCl}$-lahus) temp. $35^{\circ}$. 
lisandamine aktiviseerib käärimist, mida mangaansulfaadi lisandamine omakorda veel soodustab.

Katsetulemused HL mõjust maisiseemnete idanemisele on esitatud joonisel 3.

Nendest selgub, et HL lahjenduses 1:500 stimuleerib idanemisel juurte kasvu (pikkus, kaal) ning avaldab idandi kasvule pidurdavat toimet. Mangaansulfaadi lisandamine aga põhjustas idandi soodsamat kasvu.

HL mõju selgitamisel nahadefekti paranemisele kasutati valgeid hiiri. Katsealustele hiirtele tekitati $5 \mathrm{~mm}$ läbimõõduga trepaaniga selja tagumisel poolel depileeritud nahal tsirkulaarne defekt, mille paranemine toimub tsentrumi suunas. Uhele hiirte rühmale (5-8 hiirt) süstiti katse algul naha alla $0,2-0,4 \mathrm{ml} 0,85 \%$-list naatriumkloriidilahust, teisele rühmale sama kogus $0,85 \%$ lise naatriumkloriidilahusega lahjendatud HL. Nahadefekti paranemist jälgiti defektivälja mõõtmisega iga 2 päeva järel.

Ilmset nahadefekti paranemise kiirenemist täheldati katseseeriais, kus HL süstiti annuses $0,5-5$ mikroliitrit ühekordselt. Suuremate annuste kasutamisel $(0,01-0,2 \mathrm{ml}=$ $=10-200$ mikroliitrit) ei esinenud nahadefekti paranemise kiirenemist.

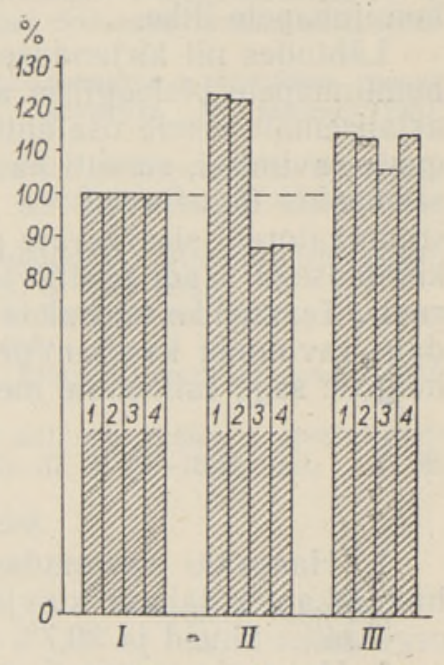

Joon. 3. $\mathrm{HL}$ ja $\mathrm{MnSO}_{4}$ mōju maisiseemnete idanemisele. 1 juure pikkus, 2 - juure kaal, 3 - idandi pikkus, $4-$ idandi kaal; I - kontroll, II - HL 1:500, III - HL $1: 500+$ $\mathrm{MnSO}_{4} \cdot 5 \mathrm{H}_{2} \mathrm{O} 2 \mathrm{mg} / \mathrm{L}$

Peale eeltoodud põhiliste näitajate kasutati HL bioloogilise aktiivsuse iseloomustamiseks veel ka katalaasi, mõjustades selle aktiivsust HL-ga. Määramisi teostati gasomeetriliselt reaktsioonikiiruse jälgimisega 15 minuti vältel. Katalaasina kasutati veise vere erütrotsüütidest N. S. Drozdovi ja V. D. Kopõlova meetodi $\left.{ }^{[8}\right]$ järgi saadud fermendilahust. $0,6 \mathrm{ml}$ fermendilahusele lisati $39,4 \mathrm{ml} 0,1 \mathrm{M}$ fosfaatpuhverlahust $(\mathrm{pH}=6,8)$ ning $20 \mathrm{ml}$ kaltsiumkarbonaadiga neutraliseeritud $1 \%$-list vesinikülihapendilahust. Lisades sellele HL, lahjenduses $1: 100$, suurenes katalaasi aktiivsus $9 \%$, võrreldes kontrolliga.

Kõnesoleva humiinhapete eraldamise katsega Haapsalu ravimudast saadi, arvestatult kuivainele, $0,7 \%$ humiinhappeid, mis on tunduvalt suurem mõnede lõunapoolsete ravimudade humiinhapete sisaldusest ning on ka kooskõlas meie ravimudade orgaanilise aine suurema sisaldusega üldse.

Arvestades asjaolu, et humiinhapped kujutavad endast väga keerulise struktuuriga kõrgmolekulaarseid aromaatseid happelise iseloomuga aineid, mille olemuse ja ühtsuse küsimused on kuni käesoleva ajani selgitamata, ei ole praegu võimalik ühe või teise lähteaine humiinhapete lähem iseloomustamine või keemiline analüüs. Seepärast osutus otstarbekohaseks iseloomustada Haapsalu ravimudast eraldatud humiinhapete fraktsiooni neile omase bioloogilise aktiivsuse mõningate näitajate kaudu. V. A. Biberi ja N. S. Bogoljubova andmetel soodustavad näiteks mustmulla humiinhapped palju tugevamini pärmi käärimisprotsessi, idanevate seemnete juurte kasvu ja nahadefekti paranemist, võrreldes turba humiinhapetega. Viimased avaldavad ainult vähest stimuleerivat toimet idandi arenemisele, pidurdades samal ajal juure kasvu pikkuses. Samade autorite järgi on limaanimuda humiinhapete bioloogiline toime võrdne mustmulla humiinhapete omaga. Mis puu- 
tub meie poolt Haapsalu ravimudast eraldatud humiinhapete bioloogilise aktiivsuse näitajate iseloomu, siis on need lähedased mustmulla ja limaanimudale. Seejuures näib tõenäolisena, et bioloogiliste näitajate hulga edasise laiendamisega võimaldub veelgi üksikasjalisemalt eristada mitmesuguseid humiinhapete liike.

Lähtudes nii kirjanduse andmeist kui ka meie endi tähelepanekutest humiinhapete bioloogilise aktiivsuse kohta, osutub vajalikuks uurida üksikasjalisemalt nende osatähtsust mudaravi faktoritena reuma ja teiste haiguste ravimisel, samuti ka nende rakendatavust ravimpreparaatidena. Seda seisukohta õigustavad rea autorite $[2,3,9,10,20]$ täheldused, kus biogeenseid stimulaatoreid sisaldavate preparaatide kasutamisega, samuti humiinhapete kümblusega saadi positiivseid tulemusi reuma ja infektsiooniliste artriitide ravil. Teaduslike uurimiste teostamist selles suunas nõuavad meilt nii laialdane ravimuda kasutamine meie vabariigi sanatooriumides kui ka reumahaiguse sage esinemine meie elanikkonnas.

\section{Järeldused}

1. Haapsalu ravimudast lihtsustatud keemilise meetodiga eraldatud humiinhapete lahuse kuivjääk sisaldab 40,4\% humiinhappeid, 28,9\% teisi orgaanilisi aineid ja $30,7 \%$ anorgaanilisi ühendeid.

2. Haapsalu ravimudast eraldatud humiinhapete fraktsioon avaldab stimuleerivat toimet pärmi käärimise, maisiseemnete idanemise, haava paranemisprotsessi ja ferment katalaasi aktiivsusse.

3. Seoses Haapsalu ravimudast saadud humiinhapete lahuse bioloogilise aktiivsuse sedastamisega osutuvad vajalikuks üksikasjalisemad uurimised humiinhapete osatähtsuse kohta mudaravi faktoreina reuma ja teiste haiguste ravil, samuti ka nende ainete rakendamiseks ravimpreparaatidena.

\section{KIRJANDUS}

1. А лекин О. А., Д а ц ко В. Г. и К онов алов Г. С., Важные задачи гидрохимии. Вестник АН СССР, 1955, № 12, стр. 82-83.

2. Бе ленький М. С. и Р у хельм ан Р. О., Грязевой раствор при лечении некоторых видов артритов. Врачебное дело 1950, № 7, стр. 613-618.

3. Бе ле ньк и й M. С., Дальнейшие наблюдения над применением грязевого раствора. Врачебное дело 1953, № 1, стр. 39-42.

4. Би бе р В. А и Богол юбов а Н. С., О биологической активности почвенной и торфяной гуминовых кислот. ДАН СССР 1951, т. 76, № 2, стр. 313-316.

5. Би бе р В. А. и Богол юбов а Н. С., Гуминовая кислота лиманной грязи и ее биологическая активность. ДАН СССР 1952, т. 82, № 6, стр. 939-942.

6. Волков а О. Ю. и Шин к а ренко А. Л., К вопросу о механизме бактерицидного действия тамбуканской грязи. Труды Государственного научно-исследовательского бальнеологического института на Кавказских Минеральных Водах. Пятигорск 1946, т. 23-25, стр. 92-99.

7. Де р бе нцев а Н. А. и Хован ов а А. М., К вопросу о химическом составе и бактерицидных свойствах эстонских лечебных грязей. Известия АН ЭССР 1955, т. 4, № 1, стр. $123-133$.

8. Д р озд ов Н. С. и К о п л ов а В. Д., Каталаза эритроцитов быка. ДАН СССР 1953, т. 92, № 1, стр. 135-137.

9. 3 в о рыкин а В. Н., Применение тканевой терапии при ревматизме. Труды Куйбышевского мединститута. 1954, т. 5, стр. 276-281.

10. Ильинский П. И., Кольпиков и Королев а Н. И., К вопросу лечения ревматизма у детей водным грязевым экстрактом. Вопросы педиатрии и охраны материнства и детства. 1950, т. XVIII, вып. 3, стр. 12-16.

Н. К и т а е р Э. Ю., О микроэлементах лечебной грязи. Изыскание и использование курортных ресурсов. Тезисы докладов научной конференции 23.-26. I 1951. Москва, 1951, стр. 55- 56.

12. К у х ренко Т. А., Гуминовые кислоты и их использование. Природа 1955, № 8 , cтр. $86-89$. 
13. С ыс оев А. Ф. и Скри п ч енко С. Н., Биологическая активность отгона из морской воды. Ученые записки т. II. Украинский экспериментальный институт глазных болезней имени академика В. П. Филатова. Киев, 1952, стр. 30-34.

14. Фи латов В. П., Би бер В. А. и А да м ан и с А. И., Определение активности биогенных стимуляторов на подъемную силу дрожжей. Ученые записки т. I. Украинский экспериментальный институт глазных болезней имени академика В. П. Филатова. Одесса 1949, стр. 106-113.

15. Ч и с тяков Н. М., О содержании некоторых микроэлементов в лечебных грязях Варзи-Ятчи. Труды Ижевского медицинского института Х. Ижевск 1951, стр. 9-12.

16. Hiller, E., Ein Beitrag zum Problem der Wirkungsweise balneologischer Massnahmen mit salizylisierten Huminsäuren. «Deutsche Medizinische Wochenschrift», 1952, 77 , Nr. $27 / 28$, S. $856-859$.

17. H iller, E., Untersuchungen zur Wirksamkeit balneologischer Massnahmen. «Deutsche Medizinische Wochenschrift», 1954, 79, Nr. 13, S. 500-503.

18. Internationales Balneologisches Kongress der ISMH in Deutschland 1952. «Schweizerische Medizinische Wochenschrift», 1954, Nr. 14, 404.

19. D e Kock, P. C., Influence of Humic Acids on Plant Growth. «Science» 1955, 121, No. 3144 , p. $473-474$.

20. Pasquali, L., Arpese 11 a, G., Considerazioni sull uso clinico c sperimentale della terapia tessutale. «Riforma med. 1953,67 , No $37,1027-1028$. Tsit. P. ЖK. Биология 1955, № 8, 20057.

21. S o u c i, S. W., Die Chemie des Moores. Stuttgart, 1938.

22. V a d i, V., Eesti tervismuda. Tartu 1947, 1k. 72-80.

Eesti NSV Teaduste Akadeemia

Eksperimentaalse ja Kliinilise Meditsiini Instituut

Saabus to metusse 22. XII 1956

\title{
О БИОЛОГИЧЕСКИ АКТИВНЫХ ВЕЩЕСТВАХ В ХААПСАЛУСКОИ ЛЕЧЕБНОИ ГРЯЗИ (ГУМИНОВЫЕ КИСЛОТЫ)
}

Э. Ю. КЕЕЛЬ

\section{Резюме}

При помощи упрощенного химического метода из Хаапсалуской лечебной грязи была выделена фракция гуминовых кислот, содержащая $40,4 \%$ гуминовых кислот, 28,9\% прочих органических соединений и $30,7 \%$ золы. Были определены некоторые биологические свойства 0,24-процентного раствора этой фракции (HL), выражающиеся в стимулирующем действии на брожение дрожжей, прорастание семян кукурузы, заживление кожного дефекта и активность фермента каталазы.

Необходимы дальнейшие подробные исследования о роли гуминовых кислот как фактора грязелечения при ревматизме и других заболеваниях, а также о возможности применения этих веществ в качестве лекарственных препаратов.

\section{Ннститут экспериментальной и клинической медицины Поступила в редакцию Академии наук Эстонской ССР \\ 22 XII 1956}

\section{BIOLOGISCH AKTIVE STOFFE IM HEILSCHLAMM VON HAAPSALU (HUMINSĂUREN)}

\author{
E. Keel
}

\section{Zusammenfassung}

Mit Hilfe einer einfachen chemischen Methode wurde aus dem Heilschlamm von Haapsalu eine Huminsäurefraktion isoliert, deren Gehalt $\mathrm{zu} 40,4 \%$ aus Huminsäuren, zu $28,9 \%$ aus anderen organischen Verbindungen und zu $30,7 \%$ aus Salzen bestand. An einer $0,24 \%$-gen Lösung dieser Fraktion (HL) wurden einige biologische Eigenschaften des Präparates untersucht, die in stimulierender Wirkung auf die Hefegärung, auf die Keimung der Maissamen, auf die Regeneration von Hautdefekten und auf die Aktivität der Katalyse bestanden. Zu betonen ist die Zweckmässigkeit weiterer Untersuchungen über die Rolle der Huminsäuren bei der Schlammtherapie des Rheumatismus und anderer Krankheiten, sowie über die Verwendung dieser Stoffe als Heilmittel überhaupt. 